\title{
Yara Guasque: do pictórico ao digital
}

\author{
Yara Guasque: from pictorial to digital
}

\author{
por Luciana Marcelino e Sandra Makowiecky
}

RESUMO

Este artigo visa analisar e registrar a transição do pictórico ao digital no pensamento e na produção da artista Yara Guasque, professora do curso de Artes Visuais da Universidade do Estado de Santa Catarina, pesquisadora em arte e tecnologia. Seu percurso artístico e intelectual parte de uma produção pictórica nos anos 80 e 90, centrada em pinturas monocromáticas de grandes dimensões com aplicação de têmpera sobre lona, na qual encontramos questões formais como cor e dimensão, que a aproximam dos artistas expressio-nistas abstratos da década de 50, especialmente com Mark Rothko, artista de maior aproximação. Transfere-se para o campo das artes digitais a partir dos anos 2000, cujos trabalhos tornam-se ainda mais experimentais e colaborativos. Percurso sintomático da atual mudança de paradigmas analógico/digital, o artigo busca ana-lisar os atravessamentos do conceito de imersão tanto na produção pictórica quanto na produção digital reali-zada pela artista. Partindo das possibilidades imersivas do campo pictórico chega-se ao estudo da imersão em telepresença nos trabalhos experimentais realizados pelos grupos Perforum Desterro e Perforum São Paulo, coordenados, respectivamente, por Yara Guasque e Artur Matuck.

Palavras-chave: imersão, pictórico, expressionismo abstrato, arte virtual, telepresença.

\section{ABSTRACT}

This article aims to analyze and record the transition from pictorial to digital in thought and produc-tion of the artist Yara Guasque, Professor of Visual Arts at the University of the State of Santa Catarina and researcher in art and technology. Her artistic career and intellectual moves from a pictorial production in the $80 \mathrm{~s}$ and $90 \mathrm{~s}$, focused on large monochrome paintings by applying tempera on canvas, in which we find for-mal questions such as color and size, that approach her work of abstract expressionist artists of the decade 50, especially Mark Rothko, artist closer. Then she moved to the field of digital arts from the 2000s, whose works become even more experimental and collaborative. Her way is symptomatic of the current paradigm shift analog /digital, the article seeks to analyze the crossings of the concept of immersion in both pictorial and digital production performed by the artist. Starting from the immersive possibilities of pictorial field comes to the study of immersion in telepresence through experimental work carried out by groups Perforum Desterro and Perforum São Paulo, coordinated respectively by Yara Guasque and Artur Matuck.

Keywords: immersion, pictorial, abstract expressionism, art virtual telepresence. 


\section{Yara Guasque: do pictórico ao digital}

\section{Introdução}

A artista plástica Yara Guasque apresenta um percurso que parte da pintura e gravura nos anos 80 e 90 para chegar à relação da arte com a tecnologia, às novas mídias e às artes digitais a partir do início do novo milênio. Com isto, conceituamos sua passagem do pictórico ao digital, entendendo por pictórico o percurso no território da gravura e pintura e por digital, o percurso que combina em grande medida arte, ciência e tecnologia. É sabido que a arte digital transformou-se numa área que agrupa todas as manifestações artísticas realizadas por um computador. Se considerarmos o advento da era digital como um momento de mudança de paradigmas, o percurso de Yara é sintomático deste processo. Este artigo pretende compreender o percurso realizado e os motivos que levaram a artista a abandonar uma pesquisa pictórica concebida em meios/suportes mais tradicionais como pintura, gravura, para se debruçar sobre o novo mundo das artes digitais.

Yara graduou-se em artes plásticas pela Fundação Armando Alvares penteado (FAAP) em 1979, desde então sua produção foi marcada pela gravura e pintura, especialmente a xilogravura e as pinturas com têmpera e aquarela. Em 1995, Yara realiza uma exposição individual no Museu de Arte de Santa Catarina ( MASC) intitulada "A questão da cor", onde a própria artista expressa que havia uma preocupação com a pesquisa cromática: "as pinturas tentam explicitar a natureza contrastante da cor".

Em relação à produção acadêmica, em 1998, Yara escreve sua dissertação de mestrado que consiste em uma análise literária sobre a obra de Coethe "Para uma Teoria das Cores". Ainda que não possamos encontrar nesta dissertação referência direta ao seu trabalho com pintura, podemos identificar relações indiretas como em uma série de trabalhos intitulados "0 mar é roxo, verde são seus olhos azuis" que segundo a artista resultaram da sua pesquisa sobre a teoria das cores. Esta série produzida entre 1995 a 2001 compõem-se de pinturas de têmpera sobre lona, gravura, painel eletrônico e um site.

A transição do pictórico ao digital também se dá no interior do pensamento e da pesquisa acadêmica de Yara. Em 2003, ela escreve sua tese de doutorado denominada "Telepresença: interação e interfaces" e em 2007 uma série intimista de desenhos e aquarelas produzidos durante quase duas décadas são apresentadas em exposição retrospectiva no Museu de Arte de Santa Catarina sob o título de "Sou alma pequenina". Atualmente, Yara Guasque é professora efetiva do curso de artes visuais da Universidade do Estado de Santa Catarina, onde desenvolve pesquisas em arte e tecnologia com o grupo Tecnofagia.

\section{Do Pictórico}

Para iniciar a abordagem teórica sobre o trabalho de Yara, vamos utilizar como ponto

1 Jornal A Notícia, Secão Variedades, terça-feira, 18 de abril de 1995, Joinville/SC. 


\section{Yara Guasque: do pictórico ao digital}

de partida metodológico o pensamento do teórico da arte Yves-Alain Bois² ${ }^{2}$ o qual sugere que o olhar sobre a obra indique os caminhos teóricos a serem percorridos. $\mathrm{Na}$ introdução do livro "A pintura como modelo", Bois faz uma crítica às diversas correntes teóricas que disputam entre si o lugar da teoria dominante. 0 autor parte da premissa de que não se deve aplicar uma teoria ao objeto de estudo, mas que a partir do objeto é que se encontra uma teoria aplicável. Com isto, ele resgata em parte um formalismo teórico abandonado após Greenberg, ao mesmo tempo em que desvincula sua teoria da obrigação de uma interpretação sociopolítica estabelecida pela geração marxista.

Bois defende que existem dois modelos teóricos que se contrapõem na história da arte do século XX e que estes o dominaram, mais acentuadamente no âmbito americano: o discurso formalista que se desenvolveu com o empreendimento de Greenberg nos anos 50 e 60 e a iconografia panofskiana. Todo esse debate, formalistas de um lado, iconologistas de outro, é tido por Bois como um sintoma daquilo que é chamado por Barthes de assimbolismo: a incapacidade de perceber a infinita proliferação semântica que forma o tecido da obra de arte ${ }^{3}$. Como se estivéssemos discutindo quantos anjos dançam na cabeça de um alfinete (WOLFE, 1987)4.

Para Bois, as correntes teóricas como a sócio-política, a psicocrítica, o antiformalismo, a iconologia, entre outras, recusam examinar a obra em sua especificidade, tratando-a como um documento, ao invés de monumento. 0 autor propõe como reação ao que ele chama de assimbolismo generalizado, o resgate do formalismo baseado na retórica russa; onde ele evoca neste formalismo uma missão essencial precisamente a definição de mediações entre o espaço semântico da obra, suas estratégias formais e tudo o que ela não é [o mundo, a história, a luta de classes, a biografia, a tradição, todo o resto] (BOIS, apud: Cotrim e Ferreira, 2001)5.

0 que então podemos perceber nas mediações entre o espaço semântico da obra de Yara Guasque, suas estratégias formais e tudo o que ela não é, ou seja, o mundo, a história, a luta de classes, a biografia, a tradição, todo o resto? Sabendo da impossibilidade de abraçar todo este conjunto, ou mesmo parte dele em um artigo, ousaremos apontar alguns caminhos possíveis.

\section{Pintura Plana}

Segundo o escritor e jornalista Tom Wolfe (1987), no período do pós-guerra, quando o ponto central da arte se desloca de Paris a Nova York, surge com força no cenário artístico norte-americano o movimento conhecido por expressionismo abstrato e a teoria da pintura plana de Clement Greenberg. A teoria da pintura plana retorna aos cubistas e

\footnotetext{
2 BOIS, Yve-Alain. A Pintura como Modelo. São Paulo, Martins Fontes. 2009.

3 BARTHES R. apud BOIS, Yve-Alain. A Pintura como Modelo. São Paulo, Martins Fontes. 2009. P. xxiv.

$4 \quad$ WOLFE, Tom. A palavra pintada. Porto Alegre: LPM, 1987.

5 BOIS, Yve-Alain. Viva o formalismo (bis), 1989. In: COTRIM, Cecília e FERREIRA, Clória. Clement Greenberg e

o debate crítico. Rio de janeiro, Zahar, 2001. P. 248
} 


\section{Yara Guasque: do pictórico ao digital}

outros modernistas, que recusaram os efeitos ilusórios da profundidade no plano, para exemplificar uma espécie de avanço teórico da arte moderna, no sentido de alcançar a pureza da pintura pela sua planitude. Ainda que os cubistas e os modernistas "primitivos" tentassem eliminar a terceira dimensão da pintura ao fugirem da figuração e do naturalismo, estes primeiros artistas abstratos mantiveram linhas, formas, contornos e cores.

Em seu ensaio Pintura Modernista de 1960, Greenberg entrega a tridimensionalidade ao domínio da escultura e considera que a pureza da pintura, a preservação de sua autonomia deveria se dar através do abandono de tudo que se pudesse compartilhar com a escultura. Assim, a arte abstrata excluiu o representativo e o literário do campo de atuação, o quadro plano. Greenberg propunha então a integridade do plano do quadro como hipótese artística para a arte moderna. Inicia-se assim uma obsessão, na opinião de Tom Wolfe, pela integridade do plano entre os pintores abstratos nova-iorquinos, tendo como suporte e sustentação a teoria de Greenberg. Considerando o expressionismo abstrato a abstração da própria abstração que foi o cubismo, a teoria torna-se combustível para a produção artística apoiando-a e reforçando-a (promovendo-a). Para Wolfe, a necessidade de uma teoria que sustente a produção artística irá seguir até o surgimento da arte conceitual como movimento, nos anos 60.

\section{Mark Rothko e a abstração imersiva - a vertente norte-americana.}

É neste cenário teórico que Mark Rothko, cuja abstração pictórica surge como produto de um processo intenso de meditação e pensamento na busca de precisão e solução de uma questão pictórica específica, centrada na cor, mas que também revela dentro dessa busca quase matemática um forte aspecto transcendente. Nesse sentido, pode-se especular as influências de Rothko advindas da pintura suprematista de Malevich. Também partindo da obra de Matisse, Rothko se dá conta de como a cor extravasa as formas impostas pela linha, inundando o quadro de vibrações vermelhas.

Rothko é o único que parece estar ligado a alguma área da arte francesa após o impressionismo, e sua habilidade em sugerir contrastes de valor e calor em oposições de cor pura me fazem pensar em Matisse, que investiu nos contrastes de valor mais ou menos da mesma maneira ${ }^{6}$.(GREENBERG, apud: Cotrim e Ferreira, 2001, p. 89). (Figura 1)

6 GREENBERG, C. Pintura à Americana, 1960. In: COTRIM, Cecília e FERREIRA, Glória. Clement Greenberg e o debate crítico. Rio de janeiro, Zahar, 2001. P. 89. 


\section{Yara Guasque: do pictórico ao digital}

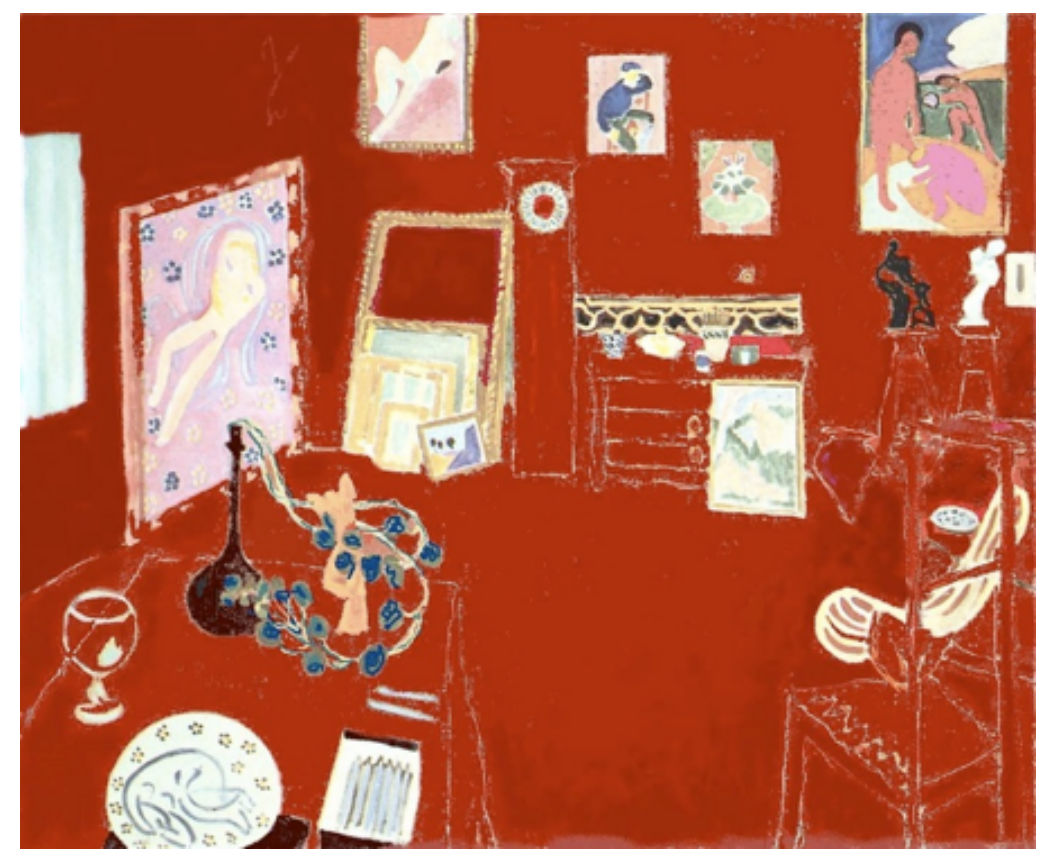

Figura 1 - Henri Matisse, The Red Studio, óleo s/ tela, 181 x 219.1 cm, 1911. Acervo online Moma7

As variadas influências de Rothko destacadas acima convergem para uma questão que consideramos primordial na sua produção: a pesquisa cromática imersiva. Destacável na obra de Rothko é o aspecto imersivo das suas pinturas abstratas. A transcendentalidade quase religiosa que atribuíram a ele diz respeito à imersão subjetiva pictórica produzida no fruidor; um perder-se entre as cores, que despertam conteúdos emocionais primários como: tranquilidade, medo, insegurança, força e êxtase. Essas possibilidades sensórias emergem conforme a vibração do campo de cor nas pinturas ${ }^{8}$. Assim, enquanto Greenberg destaca uma busca pela pureza formal na análise das pinturas expressionistas abstratas ${ }^{9}$, Rothko busca as propriedades subjetivas das cores, que se tornam indissociáveis da fruição de suas telas no sentido das sensações proporcionadas. Elas abarcam o fruidor numa expansão espacial da cor para além dos limites bidimensionais da superfície pictórica, o que abre para outras dimensões de aspectos subjetivos. (Figura 2)

Entre os críticos da pintura expressionista abstrata, não vemos uma afirmação explícita da imersividade no campo cromático, no entanto, podemos considerá-lo através de uma leitura que expressa o ilusionismo como característica destas obras. Leo Steinberg cita o escultor Don Judd para ressaltar o aspecto ilusionista presente na obra de Rothko. “Toda maneira de Rothko trabalhar se fundou numa boa dose de ilusionismo. É muito aéreo. Tudo gira em torno de massas flutuando no espaço [...] Acabei por concluir que 7 Disponível em: http://www.moma.org/collection/object.php?object_id=78389. Acesso em: 13 jun. 2013

$8 \quad$ Campo de cor ou colour field painting refere-se a um termo utilizado essencialmente para referência a alguns artistas expressionistas abstratos da década de 1950 para os diferenciar dos Action painters (como Kooning, Klein, Pollock). Os colour-field painters (como Cottlieb, Motherwell, Newman, Reinhardt, Rothko) preocupavam-se com a imagem abstrata que era constituída por uma forma ou área grande de cor unificada.

9 WOLFE, Tom. A palavra pintada. Porto Alegre: LPM, 1987. 


\section{Yara Guasque: do pictórico ao digital}

toda pintura é espacialmente ilusionista" (STEINBERG, apud: 2001) ${ }^{10}$.

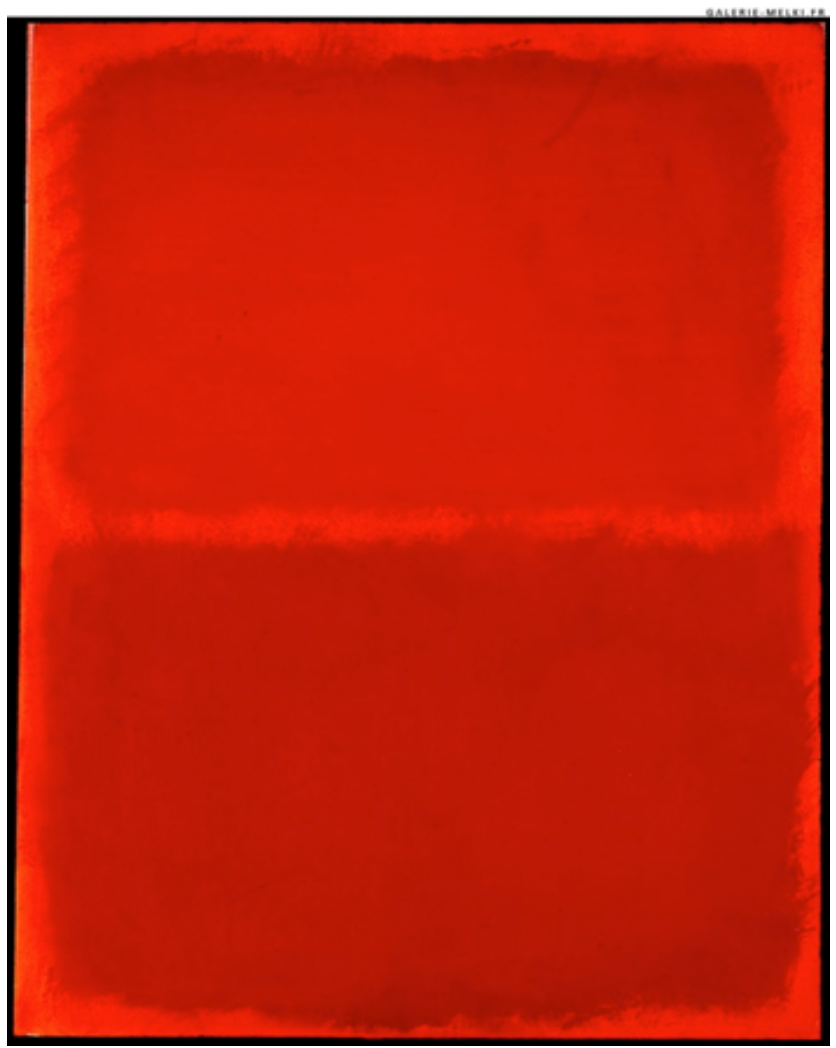

Figura 2 - Mark Rothko, Orange, red, orange, óleo sobre papel, 73 × $52 \mathrm{~cm}, 1962^{11}$.

\section{Lucio Fontana e a imersão em conceitos espaciais - vertente eu- ropeia.}

Também na Europa havia entre os artistas a necessidade de reformulações no campo da arte em decorrência dos desdobramentos da modernidade. No caso europeu, essas reformulações aparecem com maior ênfase no debate filosófico a respeito da sensibilidade do espectador em relação ao tempo, espaço e matéria; reagindo contra o caráter físico e instintivo do estilo informal, equivalente europeu do Expressionismo abstrato ${ }^{12}$. Uma contraposição crítica da teoria pintura plana proposta por Greenberg pode ser vista, por exemplo, nas obras do neo-realismo europeu, como a do italiano Lucio Fontana, que ao retalhar ou golpear suas telas, exerceu um rompimento com a bidimensionalidade da pintura para criar um espaço além dela, como em seu projeto intitulado Conceitos Espaciais produzido na década de 50 (Figuras 3 e 4). Tratam-se de pinturas em sua maioria monocromáticas que são golpeadas de modo a ampliarem a superfície

10 STEINBERG, L. Outros critérios. 1972. Paginas-175-210. In: COTRIM, C. e FERREIRA, G. Clement Greenberg e o debate crítico. Rio de janeiro, Zahar, 2001, p. 190.

11 Disponível em: http://www.galerie-melki.fr/category/artist/rothko-mark. Acesso: 03 de jun de 2013.

12 READ, Herbert. História da pintura moderna. São Paulo: Círculo do Livro, 1974. 


\section{Yara Guasque: do pictórico ao digital}

da pintura para além de sua bidimensionalidade, o que Fontana entendia pelo termo “espacialismo"(READ, 1974)'13.

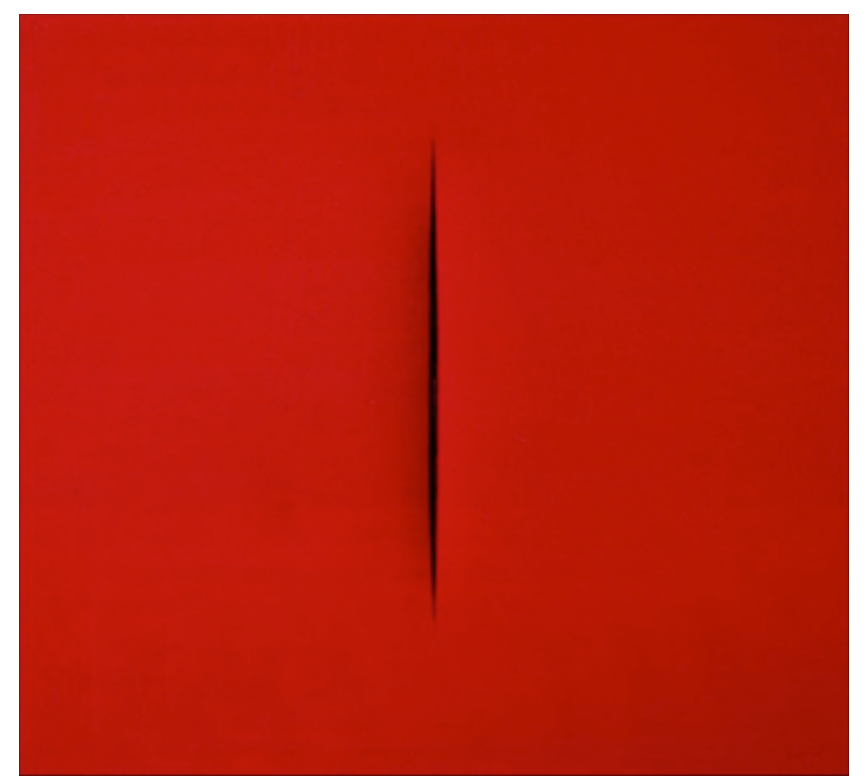

Figura 3 - Lucio Fontana, Concetto Spaziale Rosso, 29.5 × 29.5 cm, 1965.

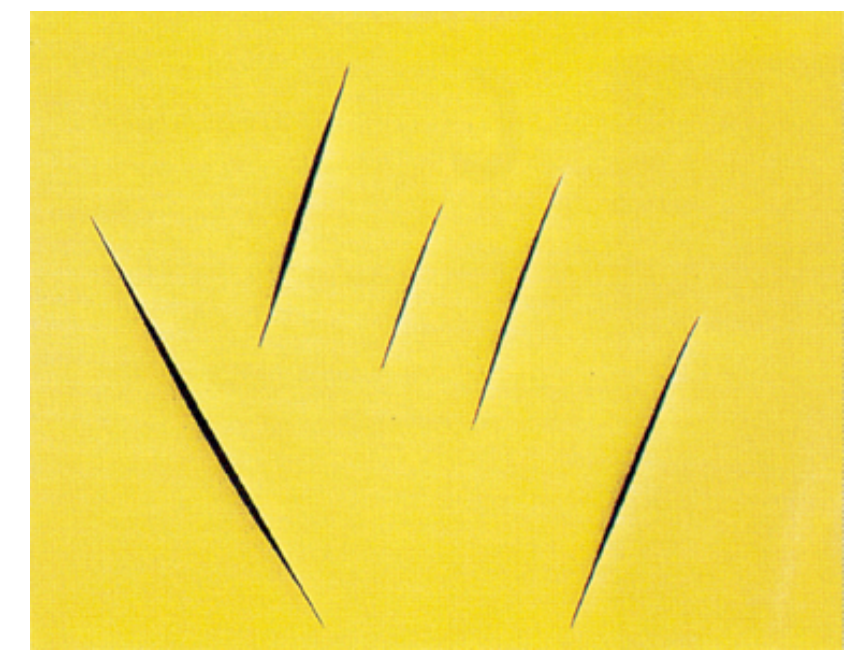

Figura 4 - Lucio Fontana, Concetto Spaziale, $100 \times 125 \mathrm{~cm}, 1959$.

No "espacialismo" a pintura ganha espaço para além da bidimensionalidade, assim ela abarca uma potência imersiva para o fruidor não mais pelo campo de cor, mas pela fissura ou rasgo do próprio espaço da obra que passa transbordar dos seus limites internos. Assim, se em Rothko os limites da pintura são extrapolados pelas intensidades vibratórias dos campos cromáticos em uma escala que abarca o fruidor, em Fontana os limites são extrapolados nos rasgos internos à tela, conferindo à pintura uma tridimensionalidade que joga entre as fronteiras pictóricas e escultóricas. Nesse sentido,

13 Idem, Ibidem. 


\section{Yara Guasque: do pictórico ao digital}

lemos duas possibilidades imersivas dadas pela cor em grandes formatos e pelo rasgo das telas.

\section{Yara Guasque e a imersão pictórica}

Yara Guasque, a nosso ver, transita ( entre outras influências possíveis) entre a vertente norte americana e a vertente européia. São influências fortes e predominantes, porém, não exatamente exclusivas. Com relação a vertente norte - americana, em 1995, Yara realiza uma exposição individual no Museu de Arte de Santa Catarina contendo uma série de pinturas de têmpera sobre lona de grandes dimensões, entre outros trabalhos. A exposição intitulava-se "A questão da cor" e segundo a artista, as pinturas daquela exposição tentavam explicitar a natureza contrastante da cor. Com estas características, o seu trabalho levanta questões relativas ao color field paintings do expressionismo abstrato norte- americano, o que a aproxima de Mark Rothko.

Para análise da produção pictórica de Yara Guasque escolheu-se três obras significativas produzidas na década de 90, presentes nesta exposição. São pinturas com aplicações em veladura de têmpera sobre lona, cujos efeitos criam campos de cor atmosféricos. Nas pinturas intituladas 0 Incerto, Rubens e Yara (Figuras 5, 6 e 7) podemos perceber algumas características formais semelhantes: formato quadrangular das telas em grandes dimensões com 1,98 m por 1,98 m; sobreposições suaves de camadas de cor baseadas em tons pastéis oscilando entre os campos cromáticos de amarelo e azul; além de traçados brancos na vertical que criam uma densidade etérea sobre o plano pictórico, uma luminosidade efusiva. Todas essas características funcionam como atratores que, a partir da sensação, descortinam uma condição imersiva para o fruidor.

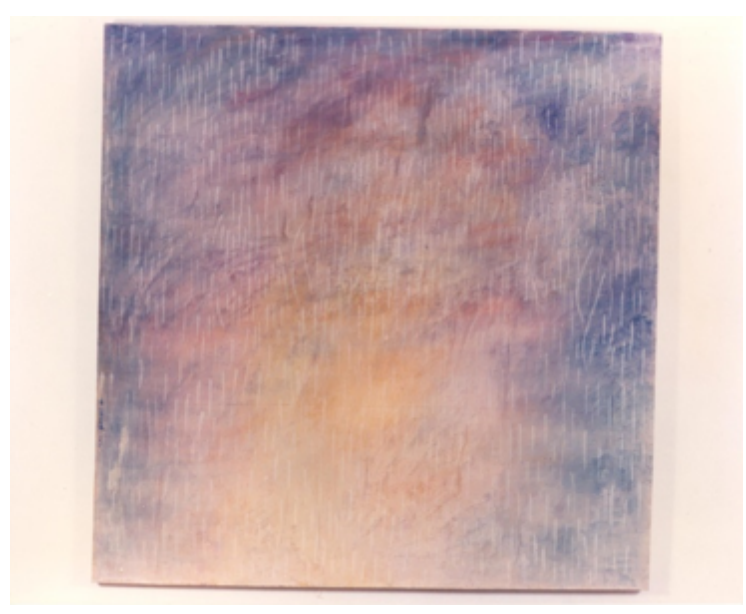

Figura 05 - Yara Guasque. 0 incerto, têmpera sobre lona, 1,98m x 1,98m 1993. Fonte: acervo da artista. 


\section{Yara Guasque: do pictórico ao digital}

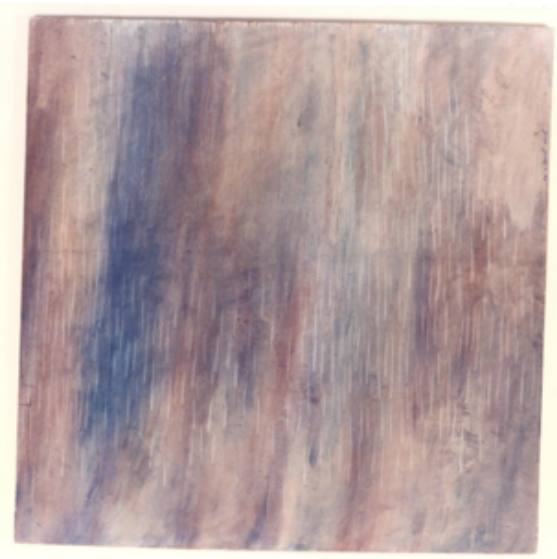

Figura 06 - Yara Guasque. Rubens, têmpera sobre lona, 0,98m x 1,98m, 1993. Fonte: acervo da artista.

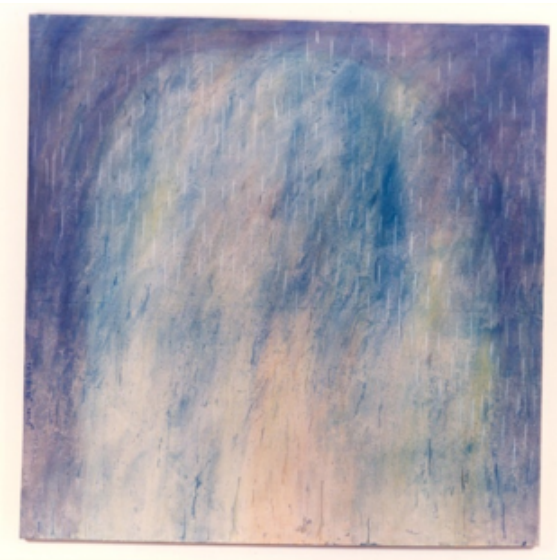

Figura 07 - Yara Guasque. Yara, têmpera sobre lona 1,98m x 1,98m 1993. Fonte: acervo da artista.

Com relação à vertente europeia, vemos outras possibilidades de aproximação. Nas pinturas das Figuras 8 e 9, Yara Guasque opera em suas composições com as duas possibilidades de imersão: a cor e o rasgo nas telas. Essas pinturas mantêm os grandes formatos com a investigação de campos cromáticos como nas telas descritas acima e agrega outro elemento compositivo, os cortes ovalados nas lonas que são sobrepostas a outras. Na pintura da figura 08 , a camada de fundo de lona possui uma cor única e chapada em tom ocre que contrasta com as cores mais dinâmicas e vibráteis da camada superior com tonalidades azuladas. Já na pintura da figura 09, o que vemos é uma complexidade da composição no sentido do uso das duas estruturas imersivas. Nela o plano de fundo é composto por cores vibráteis avermelhadas com rajadas que dinamizam e lançam a cor para fora da superfície bidimensional que, por sua vez, ocorre uma sobreposição com lona de cor azul chapado e com rasgos ovais permitindo que emerjam as cores do plano de fundo. Esses cortes também possuem no plano de fundo uma espécie de negativo, dado em espaços ovais de dimensões similares ao cortados e pintados em tons de branco. Assim as pinturas ganham pelos cortes e pelo negativo deles uma outra possibilidades dimensional, semelhante àquelas que do 


\section{Yara Guasque: do pictórico ao digital}

“espacialismo" de Fontana.



Figura 08- Yara Guasque. Sem título, têmpera sob lona, 2m x 2m, 1995. Fonte: acervo da artista.

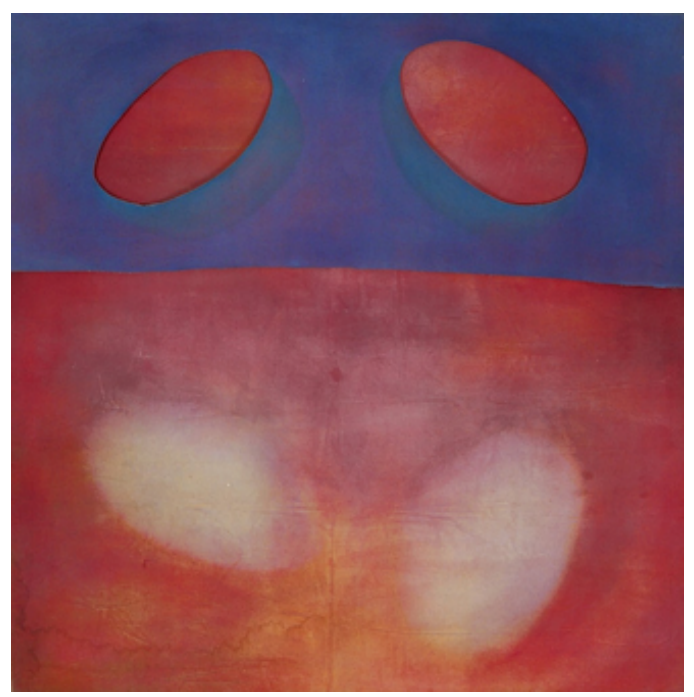

Figura 07 - Yara Guasque. Yara, têmpera sobre lona 1,98m x 1,98m 1993. Fonte: acervo da artista.

Citamos outra obra de Yara que acentua ainda mais o seu caráter imersivo, que consiste em uma instalação de um objeto relacional (Figura 10), onde o espectador entra de fato na pintura. Uma espécie de cabine de lona, pintada com têmpera no seu interior, medindo 2 metros de altura; 1,5 metros de largura e 0,7 metros de profundidade. 0 trabalho intitula-se Guaritas de Cor, uma série destes objetos foram produzidos em 1993. Trata-se de uma pintura em três dimensões, levando o espectador a uma imersão tanto pictórica quanto espacial.

Nesta trajetória brevemente delineada podemos ler nos trabalhos de Yara uma afirmação do aspecto imersivo da pintura dada tanto pelo campo cromático como pela cisão 


\section{Yara Guasque: do pictórico ao digital}

da bidimensionalidade da tela. Se por um lado a imersão ocorre de forma expandida pela vibração do campo cromático, por outro trata-se de uma imersão sintética dada pela fissura da noção tradicional do plano da pintura. Lançamos como hipótese que esse aspecto imersivo em sua obra pode ser a base para uma leitura que faz a passagem do pictórico para o digital em sua produção recente, na medida em que o digital reafirma as possibilidades imersivas em outras materialidades a partir das mídias virtuais que funciona também como campo expressivo.

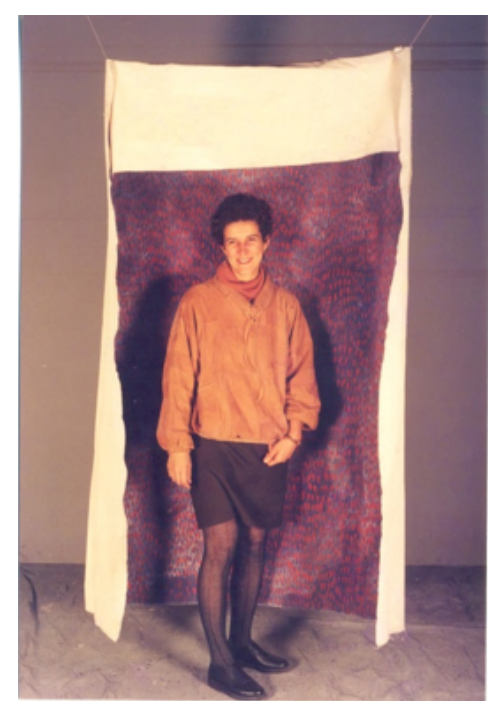

Figura 10- Yara Guasque. Guaritas de cor, instalação/objeto/espaço relacional de têmpera sob lona, $2 \mathrm{~m}$ x 0,7m x 1,5m, 1993. Fonte: acervo da artista.

\section{Do Digital}

\section{Grupo Perforum}

No final da década de 90, Yara Guasque abandona a pintura como suporte para sua pesquisa artística e em 1999 inicia seu Doutorado em Comunicação e Semiótica pela PUC de São Paulo. Ainda em 1998, Artur Matuck desenvolve, em sua disciplina Escrituras Eletrônicas, o grupo Perforum, da qual Yara participa como aluna especial. Este grupo concentrava interesses em estabelecer e efetivar núcleos interinstitucionais de diálogo em cidades distintas, trabalhando na implementação de "colaboratórios de mídia e perfomance", onde se discutiam roteiros e linguagem intermídia'14.

0 grupo Perforum acabou se tornando um projeto de rede, em que desenvolveu-se a linguagem intermídia em tempo real, unindo diversos âmbitos artísticos como as artes

14 Guasque, Yara; Araujo, Yara R. G. Perforum Desterro e Perforum São Paulo: repensando a colaboração entre a periferia e os centros, p. 01. Disponível em: 〈http://webartes.dominiotemporario.com/ performancecorpopolitica/textes\%20pdf/yara\%2operforum\%20desterro.pdf >. Acesso: 04 jul. 2013. 


\section{Yara Guasque: do pictórico ao digital}

cênicas, visuais e música para realização de perfomances de telepresença com script colaborativos $^{15}$ entre os anos de 1999 a 2001. 0 grupo Perforum era subdividido em dois pólos: Perforum Desterro, sob coordenação de Yara Guasque (entre os membros fixos do grupo Perforum Desterro estavam Daniel Izidoro, Leonardo Romão, Janaí Pereira, Cynthia Pimenta e Rodrigo Tramonte) e Perforum São Paulo, sob coordenação de Artur Matuck.

Algumas diferenças marcaram a atuação dos dois grupos. Por exemplo, conforme Araú$\mathrm{jo}^{16}$, o grupo Desterro criou sessões utilizando sistemas multicast, testadas pela RMAV-FLN, ligações discadas RDSI, streaming de vídeo em tempo real e salas multiusuários do iVisit na Internet. Os scripts colaborativos consistiam em receber as imagens de vídeo de maneira que elas fossem reelaborados nos whiteboards, que permitia o compartilhamento remoto do desenho em tempo real, e logo em seguida, reenviado, podendo ser retrabalhado da mesma maneira e cada ponto de recepção (GUASQUE, ${ }^{17}$. Ao se discutir sobre a própria natureza dos trabalhos realizados pelo grupo, chegou-se a ideia de que os eventos de performances deveriam ser assistidos com participação, onde a Internet seria o lugar de hospedagem e apresentações dos eventos em tempo real, sendo ao mesmo tempo uma manifestação de Live Art e Net Art.

Entre os anos de 1999 e 2000 foram realizadas aproximadamente 7 videoconferências, denominadas entre algumas, Linguagens Interativas e Arte Experimental, Encontro Interracial e Arte Interativa, A Economia do Amor, Evento Teleróide: artistas de lata. Estas videoconferências apresentavam diferentes scripts, co-autores e hibridização das linguagens. Segue abaixo, trecho de relato de Yara sobre um dos eventos:

\footnotetext{
"Nossa interferência no material recebido de inicio era física, analógica. Na tentativa de processarmos em tempo real as imagens recebidas, pintamos [...] em uma tela solta e transparente as imagens digitalizadas pelo codec que recebíamos de São Paulo projetadas no tecido" (GUASQUE, sem data, p 18.) ${ }^{18}$.
}

Em 2004, criou-se um grupo de pesquisa, dentro da Universidade do Estado de Santa Catarina, chamado Interações Telemáticas, com o objetivo de resgatar o material videográfico das teleperfomances realizadas pelos Grupos Perforum. Todo o material foi agrupados em três blocos denominados pelo próprio grupo de metáforas conforme o conteúdo apresentados nas performances: telefagia, esquizolinguagem e libidoeconomia ${ }^{19}$.

\section{Realidade Virtual e Telepresença}

Realidade Virtual e telepresença são palavras comuns a diferentes áreas, tais como a telerobótica, a neurociência e as artes digitais. No entanto, nos interessa aqui delinear uma breve noção deste conceitos com a finalidade discutir a imersão como conceito

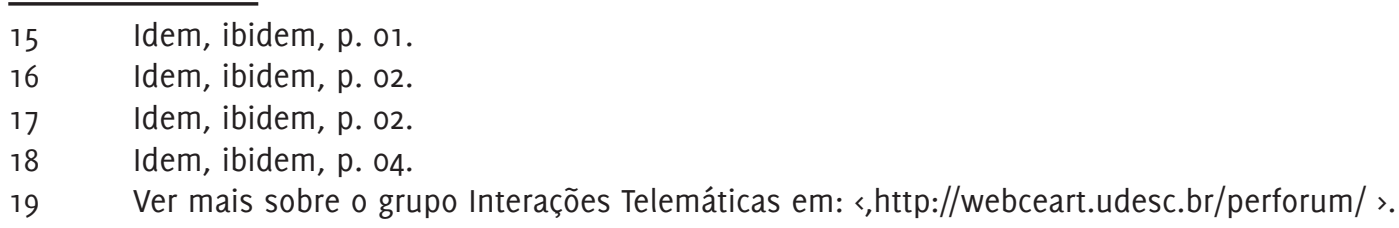




\section{Yara Guasque: do pictórico ao digital}

transversal a estes dois. Para Araújo ${ }^{20}$, realidade virtual é popularmente conhecido na situação em que o observador se sente em um mundo ficcional gerado artificialmente e a telepresença acontece quando o observador se sente em um espaço real gerado pelo ambiente natural. Ainda assim, a autora considera que existe fragilidade em tais definições.

Presença é entendido por Lombard e Ditton ${ }^{21}$ (1997) como ilusão perceptiva de não mediação. Isto porque nossa apreensão do mundo real não está isenta de mediações, o corpo e as variantes culturais são aparatos de interface que nos fazem sentir o mundo através de uma percepção fenomenológica, mediada. Se a presença física é uma ilusão de não mediação, esta não pode ser utilizada para diferenciar espaços reais de espaços virtuais. 0 objetivo mesmo da realidade virtual e da telepresença é reduzir ao máximo a sensação de mediação durante a experiência virtual de presença.

A telepresença objetiva o transporte do corpo sensorial através de suportes tecnológicos que permite, em tempo real, a comunicação dialógica desde os níveis propriocepti$\mathrm{VO}^{22}$, comum a realidade virtual, até o linguístico (GUASQUE, 2003) ${ }^{23}$. A comunicação por webcams, muito comum hoje em dia, pode ser entendida como uma operação de telepresença, no entanto é considerada nos termos de baixa telepresença, pois a imersão é limitada pelas dimensões das janelas do desktop (GUASQUE, 2003)24. Um exemplo das primeiras experimentações em telepresença citado por Grau foi realizado entre Berlim e Genebra em 1991. Um usuário em Genebra com luvas digitais podia navegar no conjunto de dados enviados por Berlim, tornando-se um experimento de telepresença relativo a recepção de obras de artes visuais e da sua interação a longas distâncias.

“A posição clássica do observador que está bem na frente de uma obra de arte material foi substituída por uma relação participativa que, apesar de transcorrida a grandes distâncias, ainda sugere a presença real diante da obra"25(GRAU, 2007, p. 307).

A partir daí, desenvolveu-se o que chamamos de arte da telepresença, como muitas ações experimentais, ainda que voltados menos para a pesquisa de ambientes imersivos do que derivados da arte telemática, estas pesquisas tiveram forte influência de dois importantes artistas: Eduardo Kac, atuante no Brasil, e Ken Goldberg, na Califórnia. Interessa-nos aqui analisar outro importante experimento de telepresença que são as video-instalações Telematic Dreaming (Figura 11), de Paul Sermon, exibida pela primeira vez em 1992, na Finlândia, trabalho que levanta questões imersivas dentro da pesquisa telemática.

20 Guasque, Yara; Araujo, Yara R. G. (Tele)+Presença e VR. Disponível em: 〈http://www.compos.org. br/data/biblioteca_914.pdf>. Acesso em: 15 jul. 2013.

21 Lombard, M.; Ditton, T. At the heart of it all: the concept of presence, 1997. Apud: idem, ibidem, p. 4.

22 Proprioceptivo é o sentido que nos dão as fronteiras do próprio corpo. In: ARAÚJ0, Y. G. R. Telepresença: interação e interfaces. P. 67.

23 Guasque, Yara; Araujo, Yara R. G. Telepresença: interação e interfaces. Editora PUC, São Paulo, 2003. P. 23.

24 Idem, ibidem. P. 27.

25 GRAU, Oliver. Arte Virtual: da ilusão à imersão. Editora UNESP, Editora Sesc. São Paulo, 2007. P. 307. 


\section{Yara Guasque: do pictórico ao digital}

Sermon fez uso da videoconferência para reunir pessoas de diferentes lugares, através da comunicação por áudio e mímica, cujos resultados de proximidade geraram uma ideia de quase-intimidade (GRAU, 2007) ${ }^{26}$. Foi utilizada uma cama como anteparo para projeção em tempo de real de uma pessoa distante ao lado de uma pessoa presente fisicamente na mesma cama. A interação em tempo real da pessoa projetada com a pessoa presente gerava uma forte sensação de proximidade. 0 efeito visual produzido pela imagem tão próxima do outro cria a sensação de tangibilidade, que conforme Grau já foi explorado por diversas vezes na história da arte, em tempos diversos e contextos distintos.

“A projeção clara de uma outra pessoa, que pode reagir em tempo real aos movimentos da pessoa na cama, é tão sugestiva que tocar a imagem do corpo, projetado sobre o lençol, torna-se um ato íntimo."(GRAU, 2007, p. 311$)^{27}$

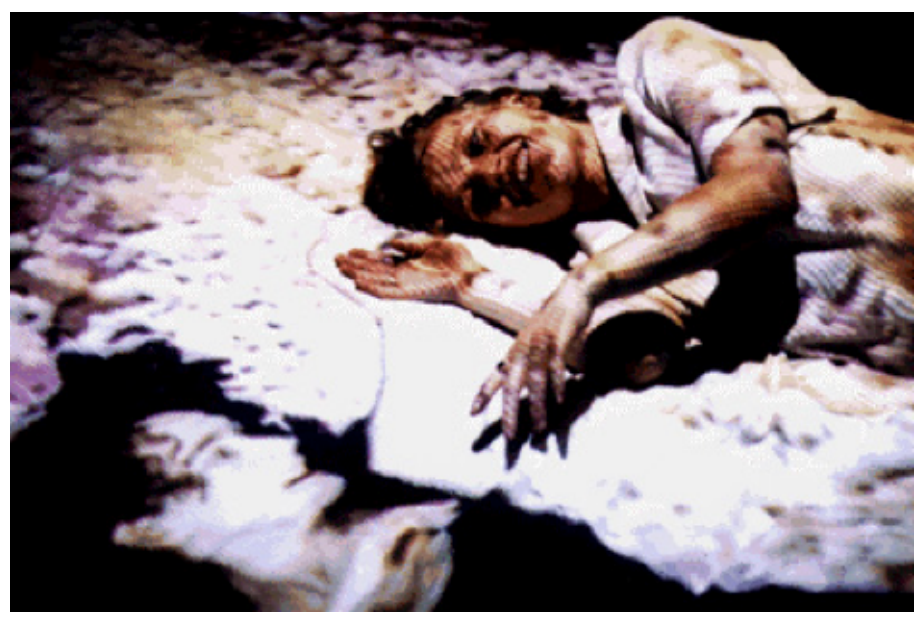

Figura 11 - Paul Sermon, Telematic Dreaming, 1992.

Invocamos o trabalho de Sermon em telepresença, especificamente o Telematic Dreaming, pois ele se aproxima da última teleperfomance realizada entre os grupos Perforum Desterro e São Paulo em 21 de maio de 2001. Nesta performance (Figura 12) a dançarina Gilsamara realiza movimentos corporais em São Paulo, interangindo com uma cobra de brinquedo manipulada por Yara Guasque, ao mesmo tempo em que desvia dos malabres de Bruno Rocha, ambos localizados em Florianópolis. A dançarina e a cobra interagem por meio da telepresença, Gilsamara não pode tocar a cobra, mas pode reagir a seus movimentos. Conforme relato de Yara:

“Na performance devolvemos a São Paulo a imagem deles com o delay característico da transmissão somadas a interação do malabar e da cobra. Estávamos enviando por RDSI e por iVisit pela internet. Tínhamos a Janaí Pereira regis-

$26 \quad$ Idem, ibidem. P. 311

27 Idem, ibidem, P. 311. 


\section{Yara Guasque: do pictórico ao digital}

trando no chat todos diálogos em tempo real e a discussão que aconteceu." 28

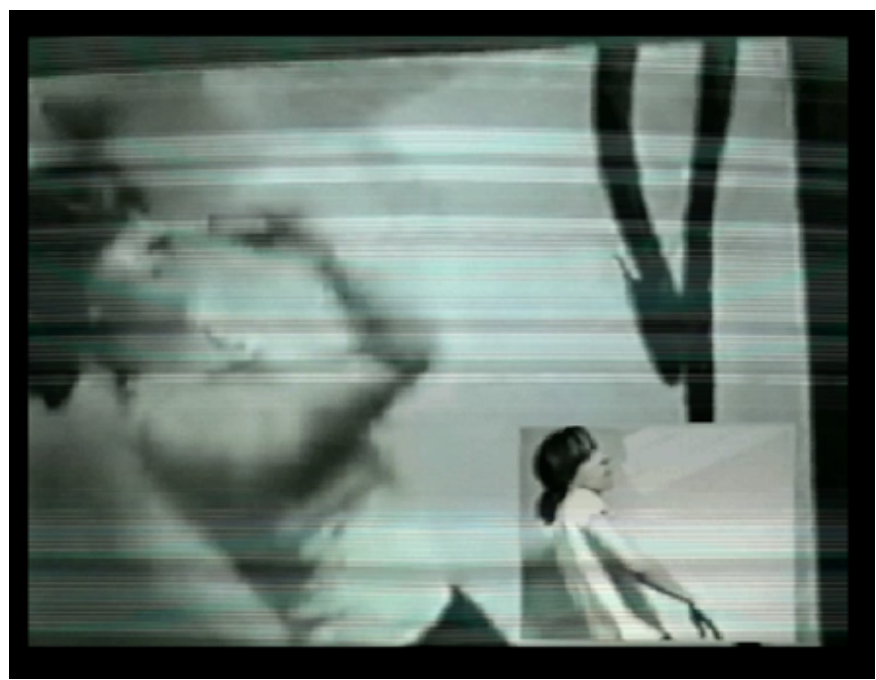

Figura 12 - Teleperformance Perforum Desterro e Perforum São Paulo, com script de Maíra Spanghero, colaborações de Daniel Seda e Bruno Rocha, 2001.

0 aspecto imersivo das teleperformances experimentais de Yara Guasque e Artur Matuck deve ser lido em seu caráter mais experimental. As intervenções em um ambiente distante por meio da telecomunicação com feedback em tempo real tornam possíveis experiências sensoriais de um evento remoto que colocam as teleperformances do grupo Perforum no âmbito da pesquisa de imersão na virtualidade. Esta experiência de um evento remoto pode ser lida, conforme Grau, como uma tentativa do desejo humano de abandonar o corpo para estar aparentemente presente e ativo em outro lugar ${ }^{29}$. Embora não fosse esta a motivação específica dos membros do grupo Perforum, esta ideia subsistiu à história não só da telepresença como também das imagens. Desde os tempos mais remotos, à imagem incumbia-se a função mágica, mitológica ou tecnológica de transportar o espectador para outra dimensão mental, espacial ou sensorial, ou seja, levar o espectador a uma imersão em outra realidade, citando brevemente como exemplo uma crença difundida no século XVIII de que com uma cabine de espelhos era possível transportar-se para esferas artificiais ${ }^{30}$. A telepresença situa-se, portanto, no âmbito tecnológico de desenvolvimento de imagens imersivas. Imersividade dada no plano da interface midiática e da experiência sensório-motora remota que contrasta com o plano subjetivo e estético da imersividade pictórica.

28 Relato por correspondência eletrônica com a artista, no ano de 2013.

29 GRAU, Oliver. Arte Virtual: da ilusão à imersão. Editora UNESP, Editora Sesc. São Paulo, 2007. P.

317.

$30 \quad$ Idem, ibidem, p. 319. 


\title{
Yara Guasque: do pictórico ao digital
}

\author{
Ilusão e Imersão
}

Oliver Grau31 apresenta, em "Arte Virtual, da ilusão à imersão" (2007) alguns conceitos importantes para o entendimento deste novo segmento no mundo das imagens e da arte. Este livro procura situar a arte virtual no contexto de uma história da arte que transita da ilusão à imersão. Ainda que a história da arte se cruzasse com a história das mídias desde os tempos mais remotos, até hoje não se deu devida atenção a este relacionamento. Para este autor, o conceito de virtualidade recai sobre as relações do homem com as imagens e como isto se evidencia no ilusionismo, onde a convergência tecnológica das imagens e das mídias guia-se por um desejo de ilusão. Acredita-se que a realidade virtual seja um fenômeno novo, produto da mais avançada tecnologia; no entanto, Grau ${ }^{32}$ procura demonstrar que a ideia de dispor o espectador diante de um espaço imagético de ilusão não é exclusividade da era dos computadores. Neste sentido, 0 autor faz uma análise de salas de afrescos da Antiguidade, do panorama do século $\mathrm{XIX}$, do cinema circular e da arte computacional. Os recursos e estratégias destas mídias convergem para a produção de um sentimento de alto grau de imersão, ou seja, um sentimento sugestivo de presença.

Para Grau, "a imersão é, sem dúvida, a chave para qualquer compreensão do desenvolvimento da mídia"33. Constitui-se como um processo mental onde a diminuição da distância crítica do que é observado relaciona-se a um crescente envolvimento emocional com os acontecimentos daí derivados. As mídias imagéticas atuam nos processos de intervenção da percepção e cognição, assim os espaços imersivos virtuais são variantes extremas destas mídias no sentido de envolver o observador numa totalidade espaço temporal, oferecendo-Ihe enfim uma realidade alternativa. 0 projeto utópico da imersão consiste em tornar invisível ou imperceptível qualquer presença de interfaces, fundindo o observador na própria mídia da imagem, afetando hermeticamente as impressões e a consciência sensorial, trata-se de um "ilusionismo a serviço do efeito imersivo" 34 .

\section{Considerações Finais}

Partindo do conceito de imersão, que entendemos como uma atitude estética que pode estar presente tanto em um substrato físico e matérico, como o pictórico, quanto em uma interface geradora de virtualidade, como no caso da telepresença, foi possível analisar a transição do pictórico ao digital que Yara Guasque realiza em seu percurso artístico. Nas pinturas de grandes dimensões, com aplicação em veladura de têmpera sobre Iona, apontamos para o aspecto pictórico imersivo, dado pela vibração de um campo cromático em combinação com a dimensão da lona, cujo efeito no espectador é de sentir-se envolvido em uma atmosfera cromática. Neste caso, seu trabalho se aproxima

\footnotetext{
31 Idem, ibidem.

32 Idem, Ibidem, p. 18.

33 Idem, Ibidem, p. 30.

34 Idem, Ibidem, p. 31.
} 


\section{Yara Guasque: do pictórico ao digital}

da pintura expressionista abstrata de Mark Rothko. Em outros trabalhos, observamos cortes ovalados na tela, que sobrepõem camadas de cor, criando um efeito de imersão espacial, onde a fissura da bidimensionalidade do espaço plano da pintura transborda para seus limites internos. Neste momento, relacionamos sua obra com as do artista italiano Lucio Fontana, que traz o espacialismo como conceito para os trabalhos em que realiza cortes nas superfícies cromáticas. Colocamos também em destaque um de seus trabalhos que evidenciam o caráter imersivo, a cabine de lona pintada, "Guaritas de cor", onde o espectador pode literalmente "entrar na pintura".

Após a análise de algumas obras significativas da produção pictórica de Yara Guasque, entramos em seu universo de estudos que trata de sua produção artística e de sua pesquisa digital. Para o estudo das noções de arte virtual e telepresença, tomamos como base o pensamento da própria artista, apresentado por meio de artigos eletrônicos e sua tese publicada, além do livro Arte Virtual do teórico Oliver Grau. Em sua produção digital, escolhemos para análise as performances realizadas pelo grupo pesquisa em telepresença Perforum Desterro e Perforum São Paulo, coordenados por Yara Guasque e Artur Matuck. Lemos, nos trabalhos experimentais do grupo, um aspecto imersivo voltado para a pesquisa de interfaces que possibilitam a experiência sensorial remota. Durante a revisão da literatura citada, percebemos a tentativa de alguns teóricos em afirmar a noção de espaço como entidade relacional de construção subjetiva individual ou coletiva. Noção que permite diluir os limites e as diferenças entre o espaço real e 0 virtual. A pesquisa realizada com a obra de Yara Guasque nos reafirma a noção do conceito de imersão escolhido, presente tanto em um substrato físico e matérico, como o pictórico, quanto em uma interface geradora de virtualidade, como no caso da telepresença.

Todavia, lembramos que Walter Benjamin (2004), em um texto de sua juventude, que permaneceu inédito até muito tempo depois de sua morte, escreveu que o tempo histórico é "infinito em todas as direções e incompleto em todos os momentos"35. 0 assunto que abordamos é ainda recente e a história que esta dimensão nos abre não nos remete a um passado já realizado e completo, repleto de fatos consumados, mas evoca a memória de um pretérito inconcluso e ainda por realizar. Sabemos que muito existe ainda por pesquisar na produção de Yara Guasque, pois sempre há um futuro oculto no passado, todo arquivo está sempre vivo e todo documento de arquivo (este pode vir a ser um deles), na oportunidade de sua redenção poética, reverbera de novas leituras.

35 Benjamin, Walter. Trauerspiel and tragedy. In: Selected writings ( vol.1).Cambridge ( Mass.): Belknap Press, 2004, p. 25. 


\section{Yara Guasque: do pictórico ao digital}

\section{Referências Bibliográficas}

> BENJAMIN, Walter. Trauerspiel and tragedy. In: Selected writings ( vol.1).Cambridge ( Mass.).: Belknap Press, 2004.

> BoIS, Yve-Alain. A Pintura como Modelo. São Paulo, Martins Fontes. 2009.

> COTRIM, Cecília e FERREIRA, Clória. Clement Greenberg e o debate crítico. Rio de janeiro, Zahar, 2001.

> GRAU, Oliver. Arte Virtual: da ilusão à imersão. Editora UNESP, Editora Sesc. São Paulo, 2007.

> Guasque, Yara; Araujo, Yara R. G. Elementos estruturais de 'Para uma teoria das cores’ de Goethe. Florianópolis, 1998. 99 f. Dissertação (Mestrado), Universidade Federal de Santa Catarina, 1998.

> GUASQUE, Yara; Araujo, Yara R. G. Telepresença: interação e interfaces. Editora PUC, São Paulo, 2003.

> GUASQUE, Yara; Araujo, Yara R. G.. Perforum Desterro e Perforum São Paulo: repensando a colaboração entre a periferia e os centros. Disponível em: <http://webartes. dominiotemporario.com/performancecorpopolitica/textes\%20pdf/yara\%20perforum\%20 desterro.pdf >. Acesso: 04 jul. 2013.

> GUASQUE, Yara; Araujo, Yara R. G. (Tele)+Presença e VR. Disponível em: 〈http://www. compos.org.br/data/biblioteca_914.pdf>. Acesso em: 15 jun. 2013.

> READ, Herbert. História da pintura moderna. São Paulo: Círculo do Livro, 1974.

> WOLFE, Tom. A palavra pintada. Porto Alegre: LPM, 1987.

Sandra Makowiecky

sandra.makowiecky@gmail.com

Luciana Marcelino, Graduanda em Licenciatura em Artes Visuais (2010) pela UDESC, participou como bolsista de iniciação científica do projeto de pesquisa Imagem-acontecimento: contemporizações da modernidade artística em Santa Catarina, da linha Teoria e História da Arte da UDESC, sob orientação da Prof. Dra. Sandra Makowiecky. luciana.ceart@gmail.com 